\title{
Obligaciones de hacer
}

Eduardo Ronald Guevara Agostinelli* http://dx.doi.org/10.21503/lex.v10i10.215

* Doctor en Derecho por la UCSM. Magíster en Derecho Civil por la UCSM. Abogado colegiado. C.A.A. Docente universitario de pregrado y postgrado en las universidades UAP, UANCV, UCSM, UJCM, Filial Arequipa.

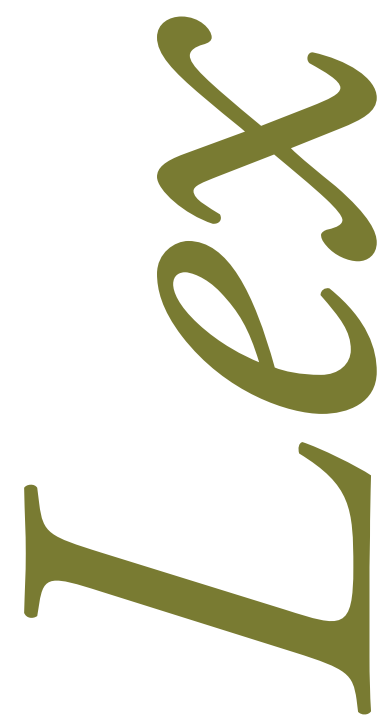




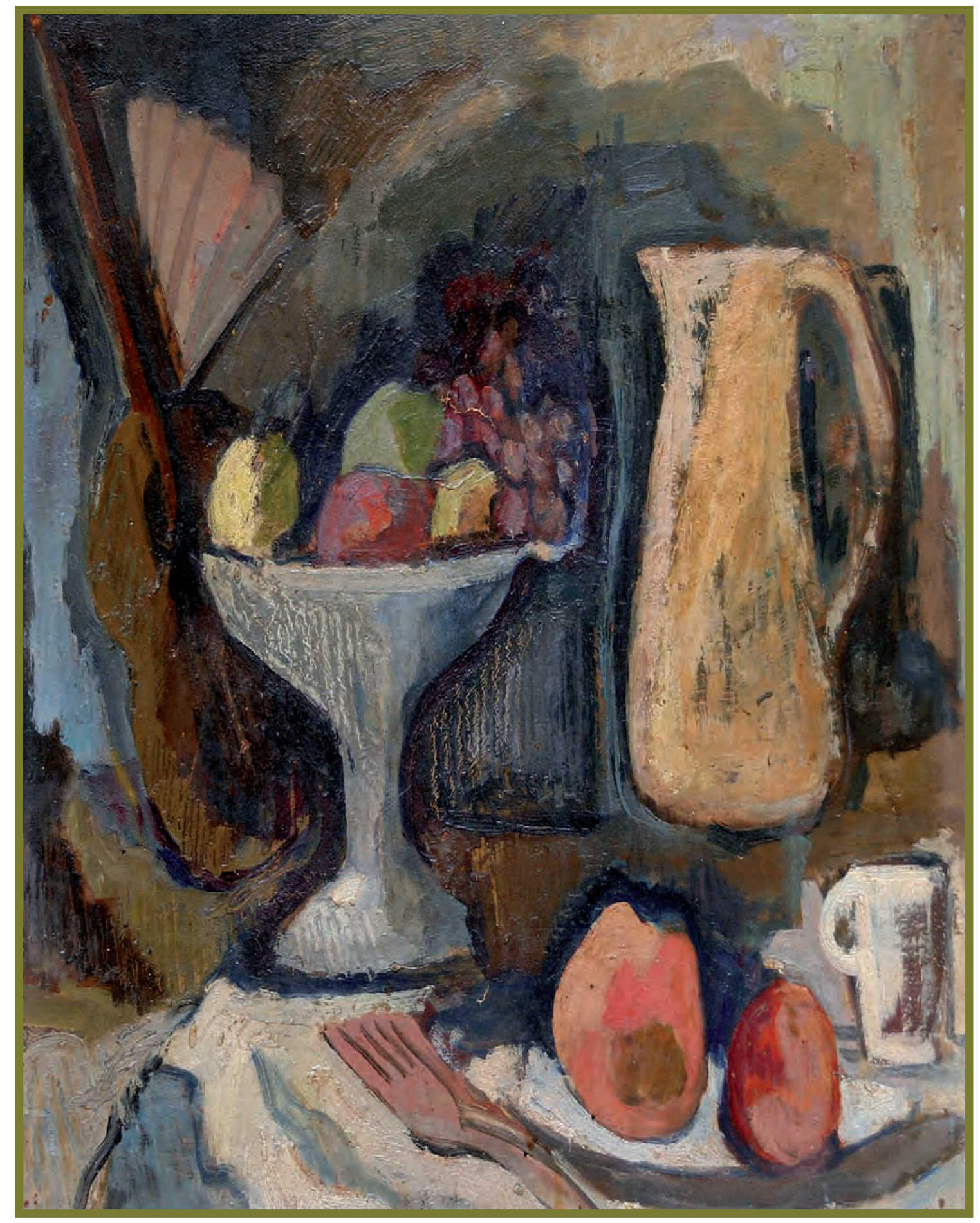

Bodegón en azul. 


\section{Concepto}

La obligación de hacer es la que recae sobre un hecho positivo, y consiste sustancialmente en una actividad realizada mediante el suministro de trabajo o energía; por ejemplo, la obligación de pintar una pared.

Hay obligaciones de hacer en el depósito, la locación de servicios, la locación de obra, el mandato, etc. ${ }^{1}$

Una prestación consiste en un hecho o acto que no entrañe ningún dar, vale decir, que no implique la transferencia de una cosa, a menos que esa transferencia (entrega, tradición, etc.) sea un simple accesorio del hecho o acto fundamental. La obligación es típicamente la que se contiene en la prestación de un servicio (profesional, etc.) o en la ejecución de una obra (una casa, un libro, un puente, un camino, etc.), particularmente cuando el locador o empresario no pone los correspondientes materiales. ${ }^{2}$

\section{Plazo y modo de cumplimiento}

El art. 1148 establece que el obligado a la ejecución de un hecho debe cumplir la prestación en el plazo y modo pactados o, en su defecto, en los exigidos por la naturaleza de la obligación o las circunstancias del caso. Conviene aclarar que los principios del plazo y modo son comunes a todo el derecho obligacional. Sin embargo, en las obligaciones de hacer, ellos suelen tener mayor significación.

En la obligación de hacer, el tiempo y el modo son, usualmente, esenciales, lo que no ocurre con igual frecuencia en las obligaciones de dar, en las que algún retraso en el cumplimiento de la obligación o alguna modificación en el modo pueden ser irrelevantes.

1 Alterini, Ameal y López Cabana. Derecho de obligaciones civiles y comerciales. Reimpresión, Buenos Aires: Abeledo-Perrot, 1993, pp. 480 y 481.

2 Alfredo Colmo. De las obligaciones en general. Tercera edición, Buenos Aires: Editorial Kraft, 1944, p. 242. 
Colmo, refiriéndose al modo, dice que es capital en estas obligaciones, a diferencia de lo que ocurre con las de dar, en las cuales lo primordial es la cosa misma en que estriba la prestación y no el modo de su entrega, por cuanto ese modo no va a desvirtuar la prestación. Aquí lo modal del hecho forma parte indisoluble del hecho mismo: no me hace el libro quien me escribe un libro de cosas adocenadas, no levanta el puente de mampostería convenido quien construye un puente de hierro o de barcas, no hace el camino acordado quien lo hace entre los puntos $\mathrm{X}$ y $\mathrm{Z}$ cuando yo lo quería entre los puntos $\mathrm{A}$ y $\mathrm{B}$, no me hace la casa prometida quien pretende endosarme un adefesio sin arte, etc.

Existirán obligaciones en las cuales el cumplimiento por parte del deudor dentro del plazo establecido será de mayor importancia que en otras. Por ejemplo, si la obligación consistiese en dar una suma dineraria el día 27 de mayo a las 5 de la tarde y el deudor efectuase dicho pago a las 6:15, lo más probable es que dicha demora no cause mayores inconvenientes al acreedor (aunque podría ocurrir lo contrario). De otro lado, podríamos tener una obligación de hacer por la cual un determinado cantante se comprometa a dar un concierto el 29 de mayo a las 7:00 de la noche. En este caso, resulta evidente que si el cantante no se aparece a esa hora sino a las 11:30 de la noche, habrá causado muchos inconvenientes y de seguro daños y perjuicios a su acreedor. De ahí la importancia del plazo y el respeto del mismo.

La naturaleza de la obligación alude a las condiciones en que generalmente, o de acuerdo con el caso en particular, deba ser ejecutada una obligación de la naturaleza de la que se ha celebrado.

Para el caso en que se trate de un contrato con prestaciones recíprocas, la naturaleza de la prestación, el modo y el plazo deberán estar en directa relación con el contenido de la contraprestación a recibir.

Las circunstancias del caso están íntimamente relacionadas con la naturaleza de la obligación (o mejor dicho de la prestación que constituye su objeto), pero no están referidas a la generalidad de prestaciones y a la prestación en concreto, sino solamente a este último supuesto. ${ }^{3}$

\section{Posibilidad de ejecución de la prestación por un tercero}

El art. 1149 dice que la prestación puede ser efectuada por cualquier persona, tenga o no interés en el cumplimiento de la obligación, sea con el asentimiento del deudor o sin él.

Este principio se sustenta en que al acreedor le es indiferente que la obligación sea cumplida

3 Felipe Osterling Parodi y Mario Castillo Freyre. Tratado de las obligaciones. Lima: Fondo Editorial PUCP, 1994, pp. 190 a 195. 
por el propio deudor o por un tercero, en la medida en que tal cumplimiento satisfaga lo pactado.

Sin embargo, la parte final del precepto establece una excepción importante. Este se refiere a las obligaciones intuitu personae. En las obligaciones de hacer ocurre con frecuencia que ellas se contraigan teniendo en consideración calidades que son inherentes al deudor, por referirse a sus atributos personales.

Es evidente, en estos casos, que el hecho deberá ser cumplido por el propio deudor; la obligación no podrá ser ejecutada por un tercero, porque ella se contrajo teniendo en consideración las aptitudes personales del deudor o su habilidad para el hecho prometido.

Lo mismo ocurre, y así lo señala expresamente el Código, cuando, no obstante que la obligación no es por su naturaleza intuitu personae, se le atribuye tal calidad a mérito del pacto. $^{4}$

\section{Acciones que corresponden al acreedor ante el incumplimiento del deudor}

$\mathrm{El}$ art. 1150 regula el régimen del incumplimiento total de las obligaciones de hacer. El incumplimiento se ubica en el supuesto de que exista dolo o culpa del deudor. La ausencia de culpa determinaría la ausencia de responsabilidad.

Proporciona al acreedor, ante el incumplimiento de la obligación de hacer, la posibilidad de optar por una cualquiera de las tres medidas allí previstas:

a) Exigir la ejecución forzada, a no ser que fuese necesario para ello emplear violencia contra la persona del deudor.

b) Exigir que el hecho sea ejecutado por persona distinta del deudor, pero por cuenta de este.

c) Dejar sin efecto la obligación.

Las dos primeras opciones no siempre están al alcance del acreedor. En el primer caso, porque las obligaciones de hacer que se ejecutan forzadamente, sin ejercitar violencia contra la persona del deudor, pueden no ser frecuentes, por referirse usualmente a aquellas que se traducen, luego de la ejecución del hecho, en la entrega de una cosa.

Se cita como ejemplo el siguiente caso: "Si un individuo se compromete a abandonar en determinado tiempo una casa que ocupa y luego se niega a hacerlo, resulta evidente que la

4 Felipe Osterling Parodi y Mario Castillo Freyre. Tratado de las obligaciones. Lima: Fondo Editorial PUCP, 1994, pp. 324 y 325. 
obligación obtendrá pleno cumplimiento desalojando al deudor y conduciéndolo fuera de la casa con el auxilio de la fuerza pública; el cumplimiento de la obligación sería posible y no habría más violencia que la que se emplea en la ejecución de los bienes del deudor por una obligación de dar, si el obligado se resiste”.

La segunda opción no sería factible porque la medida está descartada en las obligaciones que se han concertado intuitu personae. $\mathrm{Y}$ aun cuando no se tratara de obligaciones de esta clase, el acreedor tendría que recabar, en todo caso, autorización judicial previa, a fin de que el hecho pudiera ser practicado por un tercero a costo del deudor. Muchas veces, la premura del acreedor por el cumplimiento de la obligación de hacer o lo determinante del tiempo y modo a los que se refiere el art. 1148 impiden optar por esta vía.

Luego, el acreedor que ve defraudados sus derechos no tendrá otra alternativa que invocar la resolución del contrato por incumplimiento del deudor, vale decir, lo previsto por el inc. 3 del art. 1150.5

\section{Cumplimiento parcial, tardío o defectuoso por culpa del deudor}

El art. 1151, por su parte, prevé los casos de cumplimiento parcial, tardío o defectuoso de la obligación de hacer.

En tales situaciones, el acreedor, según la naturaleza del caso y su propia voluntad, tiene las siguientes opciones:

a) Exigir la ejecución forzada del hecho prometido, a no ser que sea necesario para ello emplear violencia contra la persona del deudor.

b) Exigir que la prestación sea ejecutada por persona distinta al deudor y por cuenta de este.

c) Considerar no ejecutada la prestación, si resultase sin utilidad para él.

d) Exigir al deudor la destrucción de lo hecho o destruirlo por cuenta de él, si le fuese perjudicial. Si se opta por este camino, se requeriría de una resolución judicial que faculte al acreedor a actuar así. De lo contrario, no podría cobrar al deudor lo gastado. En este caso, el acreedor cobraría vía indemnización de daños y perjuicios, cuyo monto es discrecional.

e) Aceptar la prestación ejecutada, exigiendo que se reduzca la contraprestación, si la hubiere. ${ }^{6}$

5 Felipe Osterling Parodi y Mario Castillo Freyre. Tratado de las obligaciones. Lima: Fondo Editorial PUCP, 1994, pp. 326 y 327.

6 Felipe Osterling Parodi y Mario Castillo Freyre. Tratado de las obligaciones. Lima: Fondo Editorial PUCP, 1994, pp. 235 a 242 . 
Se observa que el art. 1151 contiene un principio similar al art. 802 del Código portugués, esto es, que el acreedor no puede resolver la obligación si su cumplimiento parcial tuviese escasa importancia. El precepto solo autoriza al acreedor a tener por no ejecutada la prestación si esta le resultara inútil. El cumplimiento parcial de escasa importancia no originaría, en definitiva, la inutilidad de la obligación, sino únicamente la reducción de la contraprestación, si la hubiere.

\section{Indemnización de daños y perjuicios}

Como hemos expresado al analizar los preceptos anteriores (arts. 1150 y 1151), al acreedor que se viese perjudicado por el incumplimiento total de la prestación o por un cumplimiento parcial, tardío o defectuoso, le asiste el derecho al reembolso de los daños y perjuicios que dicho incumplimiento le hubiese ocasionado (art. 1152).

De acuerdo con la doctrina, es evidente la razón que sustenta el principio recogido por el art. 1152, ya que siendo la obligación un lazo de derecho, no puede haber obligación cuando aquel que ha prometido hacer o no hacer una cosa puede dejar impunemente de hacerla. Agrega que, obviamente, puede dejar impunemente de ejecutarla, cuando yo no tengo interés alguno justipreciable de que haga o no lo que ha prometido, pues que de ello no puede resultar para con él indemnización de daños y perjuicios por la inejecución de su promesa, ya que la indemnización de daños y perjuicios no es otra cosa que la estimación del interés que tiene el acreedor en la ejecución de la obligación.

Debe tenerse en cuenta que la obligación de indemnizar daños y perjuicios al acreedor no es una facultad del deudor, quien, tal como lo expresa Luis María Boffi Boggero, no puede librarse del cumplimiento de la obligación ofreciendo el pago de un resarcimiento. Esto equivale a decir, en palabras del autor citado, que no puede ofrecer la sanción para cometer el ilícito.

Los arts. 1150 y 1151 estén referidos a supuestos de incumplimiento debido a culpa (leve o inexcusable) o dolo del deudor.

La imposibilidad de ejecución podría haberse originado por una disposición de la autoridad, como la prohibición de construir un edificio, caso en el cual no sería ni ejecutable ni habría culpa del deudor. ${ }^{7}$

El resarcimiento de los daños y perjuicios solo procede cuando el acreedor realmente los ha sufrido. El incumplimiento de una obligación que no origina daños y perjuicios tampoco

7 Felipe Osterling Parodi y Mario Castillo Freyre. Tratado de las obligaciones. Lima: Fondo Editorial PUCP, 1994, pp. 246 a 249 . 
confiere título al acreedor para exigir el resarcimiento. Valgan, como excepción, los casos de las obligaciones con cláusula penal. ${ }^{8}$

\section{Jurisprudencia: Obligación de Hacer}

Diálogo con la jurisprudencia, año 5, número 14, noviembre de 1999, Gaceta Jurídica Editores, Lima, 1999, pp. 137 a 140.

Casación No 278-98. Lima. Sala Civil Transitoria de la Corte Suprema. El Peruano: 26-11-98. Cuando se opte por lo establecido en el inc. 2 del art. 1150, es decir, exigir que la prestación sea ejecutada por persona distinta al deudor y por cuenta de este, para hacer una correcta interpretación de esta norma debe tenerse en cuenta dos situaciones: primero, cuando no se trata de caso urgente, debe obtenerse autorización judicial para la ejecución del hecho debido, en cuya hipótesis el costo del cumplimiento de la obligación podrá obtenerlo el acreedor bajo el concepto de gastos de la ejecución por otro, más la exigencia de un pago indemnizatorio; y segundo, cuando se da esa urgencia es posible prescindir del órgano jurisdiccional, para proceder por sí mismo o por un tercero, previa constitución en mora del deudor. (Código Civil, primera edición, Gaceta Jurídica, Lima, 2001, p. 210). 


\section{CONCLUSIONES}

1. Las partes pueden crear toda clase de obligaciones utilizando para ello tanto los contratos típicos como los atípicos, salvo las excepciones establecidas por ley.

2. La obligación debe ser lícita, pues si fuera contraria al orden público, las buenas costumbres y en general a la ley, sería ilícita y con ello arrastraría su invalidez.

3. Al crear obligaciones, las partes se están obligando a dar, hacer o no hacer algo. Estas obligaciones generan el cumplimiento de determinadas prestaciones cuyo objeto pueden ser bienes o servicios.

4. Las obligaciones de dar y hacer surgen en el Derecho Civil como la necesidad de proteger tanto al acreedor y al deudor frente al incumplimiento de cualquiera de ellos.

\section{SUGERENCIAS}

1. En el análisis decimos que en el Código peruano, la doctrina y la jurisprudencia expresan claramente todos los aspectos de este tipo de obligaciones, dando a cada una de ellas subtipos explicados y detallados a fin de no dejar espacios en blanco para una posible liberación de las obligaciones que adquirimos las personas o cuando somos acreedores y otras personas tienen que cumplir con sus obligaciones. Al efecto, se detallan las situaciones en las cuales uno puede librarse de ciertas obligaciones sin tener un perjuicio detrás de este incumplimiento.

2. Sin embargo, entendemos que el legislador ha sido meticuloso y detallista a la hora de legislar sobre esta parte del Derecho Civil; por lo tanto, la parte tratada de obligaciones se halla en este trabajo tratada de forma amplia y detallada en todos sus aspectos.

3. En el Código Civil peruano, aunque es perfectamente posible demostrar que el contrato tiene efectos reales, continúan exhibiéndose, y en demasía, normas repetitivas de una tripartición que en la actualidad es a todas luces cuestionable (las obligaciones "de dar", "de hacer", "de no hacer") y en algunos casos hasta inútil. 


\section{REFERENCIAS}

- Alterini, Atilio, Aníbal; Ameal, Oscar José y López Cabana, Roberto M. Derecho de obligaciones civiles y comerciales. Cuarta edición, segunda reimpresión, Buenos Aires: Abeledo-Perrot, 1993.

- Colmo, Alfredo. De las obligaciones en general. Tercera edición, Buenos Aires: Editorial Guillermo Kraft, 1944.

- Borda, Guillermo A. Manual de obligaciones. Décima edición actualizada, Buenos Aires: Editorial Perrot, 1994.

- Osterling Parodi, Felipe y Castillo Freyre, Mario. Tratado de las obligaciones. Volumen XVI, primera parte, tomo II, primera edición, Lima: Fondo Editorial de la PUCP, 1994.

- Exposición de motivos y comentarios del Código Civil. Parte III, tomo V, tercera edición, Lima: Grafotécnica Editores e Impresores, 1988. Compiladora: Delia Revoredo de Debakey.

- Diálogo con la Jurisprudencia. Año 5, número 14, noviembre de 1999, Lima: Gaceta Jurídica Editores, 1999. 